The Impact of Emotions on Romantic Judgments: Sequential Effects in a Speed-dating Study

Laura Sels

Eva Ceulemans

Madeline Pe

Peter Kuppens

KU Leuven - University of Leuven

Author note Correspondence concerning this article should be addressed to Laura Sels, Faculty of Psychology and Educational Sciences, University of Leuven, Tiensestraat 102, box 3713, 3000 Leuven, Belgium.

E-mail: Laura.Sels@kuleuven.be

Telephone number: (+32) 16329756

Acknowledgments: This research was supported by the Research Fund of the University of Leuven (Grants GOA/15/003; OT/11/031), by the Interuniversity Attraction Poles programme financed by the Belgian government (IAP/P7/06), and by a research grant from the Fund for Scientific Research-Flanders (FWO, Project No.

G.0582.14 awarded to Eva Ceulemans, Peter Kuppens and Francis Tuerlinckx). 


\begin{abstract}
How do our feelings impact the romantic judgments and decisions we make? In a speeddating context, where people have to judge potential romantic partners sequentially, we investigated if and how participants' prior affective state guided romantic desire towards, and actual choice for an interaction partner. We found evidence for contrast effects, meaning that romantic judgments contrasted with the affective states participants were in at the start of a new interaction. The more positive (excited, interested or happy) participants felt after one interaction partner, the less attracted they were towards a new interaction partner, and the more negative they felt (irritated or bored), the more attracted they were. The effect of negative emotions was primarily visible in men, for whom more prior negative emotions even increased the chance of choosing an interaction partner at the end of the evening. The effect of positive emotions however had faded away when people chose their date at the end.

Additional analyses revealed that specific emotions showed differential effects on romantic desire and actual choice; and that contrast effects were mediated but not fully explained (at least in the case of positive emotions) by desire towards the previous interaction partner.
\end{abstract}

Keywords: dating, emotion, feelings, judgment and decision making, romantic attraction 
The Impact of Emotions on Romantic Judgments: Sequential Effects in a Speed-dating Study

Imagine you are single, and standing in a bar. A potential partner approaches you, and although you find this person very irritating, you are obliged to interact with him/her. This impacts your mood accordingly, and you start to get in a bad mood. Will the person who approaches you next, suffer from your aversion and will he/she be judged more unfavorably than otherwise would be the case, or quite the opposite, will he/she actually benefit from this, being rated more favorably?

How we feel has a strong impact on the judgments and decisions that we make, ranging from what to buy to who to like (Blanchette \& Richards, 2010; Han, Lerner, \& Keltner, 2007; Isen, 2001). In many cases, such decisions have to be made in quick succession, in which the response to one option can serve as input for a decision about the next. Also in the context of romantic choices, people often interact with and thus have to evaluate potential partners in quick succession. Individuals are often exposed to and end up talking with different potential targets during the same evening at parties, bars, or other social settings. On dating websites and apps, there is even an explicit sequential presentation of potential partners. For example, on the extremely popular app "Tinder", people use a swiping motion to choose between the photos of other users, and hence between whom they would like to get to know, implying that the next potential partner is only one click away. Additionally, singles are often communicating, texting or chatting with multiple interested persons simultaneously (Finkel, Eastwick, Karney, Reis, \& Sprecher, 2012). Finally, there is the possibility to attend speeddating events, where each person has a series of brief "dates" with other attendees, and chooses at the end of the evening whom he/she wants to meet again. 
In such complex, sequential environments, how are people's judgments influenced by their feelings? Will their evaluative judgments be in line with the mood they were in upon meeting someone new (evidencing emotion congruent or assimilation processes), or will it contrast with it (evidencing emotion incongruent or comparison processes)? In the present study, we examined if and how people's prior feelings serve as input for judging the attractiveness of potential dating partners in a speed-dating context.

\section{Emotions and judgments}

How we feel impacts our subsequent judgments and how we will perceive, interpret and remember others (Bower, 1981; Bower, 1991; Clore, Schwarz, \& Conway, 1994; Forgas, 1995; Forgas, 2008; Forgas \& Bower, 1987), making it very likely that these feelings will also influence judgments about initial romantic desire. Surprisingly, the role of emotion in judgments on romantic desire has been studied very little. Researchers have mainly focused on more stable perceiver characteristics (i.e. characteristics of the person making judgments), such as physical attractiveness, personality, sex, et cetera (see Finkel \& Baumeister, 2010 for an overview). Therefore, it is unclear how prior emotions would affect judgments about romantic desire, and certainly in a serial dating context, in which people do not only experience emotions in the presence of their current interaction partner, but also experience feelings due to the persons coming before. Interestingly, this specific context can lead to contrasting predictions about how one's feelings would affect romantic desire and choice.

\section{Emotion congruent judgments versus emotion incongruent judgments}

When it comes to social judgments, there is abundant evidence for mood-congruity biases. How people feel guides their judgments of social encounters accordingly, because congruent content is primed or because individuals use the emotion directly as information to inform their judgments (Bower, 1981, 1991; Clore et al., 1994; Forgas, 1995, 2008). In a study of 
Forgas and Bower (1987), for instance, a positive or negative mood was induced by giving participants false positive or negative feedback on a psychological test. Participants were then presented several person descriptions, and participants in a happy mood paid more attention to positive details, and formed more favorable person impressions than participants in a sad mood. In other studies, positive and negative mood-inductions that were unrelated (Gouaux, 1971) or associated to the person being judged (Gouaux \& Summers, 1973) resulted in according changes in evaluations of a stranger. People's emotional state guides the way in which observed behaviors in others are spontaneously perceived and encoded (Forgas, Bower, \& Krantz, 1984), and activates a predisposition to appraise new events and objects in ways that are consistent with the original emotion (Lerner \& Keltner, 2000).

On the one hand, this body of literature would thus suggest that prior emotions would elicit emotion congruent judgments for romantic desire towards a person, by a subsequent bias for valence congruent responses. On the other hand, the same literature also suggests conditions in which experienced emotions would elicit valence incongruent judgments later on, referred to as contrast effects (Schwarz, 2011; Schwarz, Strack, Kommer, \& Wagner, 1987). Specifically, the inclusion/exclusion model of Schwarz and Bless (2007) states that people often rely on a comparison or reference standard to arrive at a judgment of a target (i.e. the person being judged). Subsequently, affective influences that are used in constructing this standard would provoke contrast effects, whereas affective influences that are used to make constructions of the target itself would produce congruent or assimilation effects. For instance, in one experiment, participants rated their own love life more favorably after watching a sad love movie, although this movie induced a negative mood (Abele \& Gendolla, 1999). The emotion-inducing event (e.g., love movie) was a meaningful standard of reference, and participants probably used it as a comparison standard for the evaluation of their own love live (Abele \& Gendolla, 1999; Schwarz, 2011). 
In daily life, there are often situations in which emotions can be used to form a comparison standard for subsequent person judgments. This is especially the case for sequential judgments and decisions, which occur in a wide variety of settings: employee hiring, evaluations in sport competitions, oral examinations, judges evaluating a series of defendants, driving examiners judging multiple candidates, et cetera. How a perceiver is feeling right before meeting one person, is then partly due to the persons that came before, which can elicit comparison processes in which people compare the new person with the previous ones. For romantic desire in a serial dating context specifically, this means that one's prior emotional state can be used as a relevant comparison standard, therefore resulting in emotion-incongruent judgments.

Although contrast effects in judgments about person-perception have been under investigated for perceiver characteristics such as experienced emotion, they have been wellestablished for target characteristics (for overviews, see Schwarz \& Bless, 1992; Bless \& Schwarz, 2010). For instance, after being presented with untrustworthy (Bless, Igou, Schwarz, \& Wänke, 2000), very physically attractive (Kenrick \& Gutierres, 1980; Kenrick, Gutierres, \& Goldberg, 1989), or unresponsive targets (Spielmann \& MacDonald, 2016), people judge the next targets they are exposed to as more trustworthy, less attractive or romantically interesting, or more responsive. In a speed-dating context specifically, people have shown to report less romantic interest in a potential partner after interacting with somebody who was considered as more physically attractive by independent raters (Barghava \& Fisman, 2014). What makes emotions different from these already investigated characteristics, however, is that emotions are not stable individual differences that characterize the targets, and that people in general agree on (Finkel \& Baumeister, 2010). Emotions inherently belong to the perceiver, and they are not only subjective, but also change continuously over time, and are 
impacted by multiple processes simultaneously. Still, they are one of the most important sources people rely on to form a judgment (e.g., Forgas, 1995).

\section{Study and research questions}

In sum, theoretical frameworks suggest different hypotheses about the impact of a perceiver's prior emotional state on reported desire to a potential partner. On the one hand, people tend to maintain their emotional states by congruent appraisals (e.g., Lerner \& Keltner, 2000), often resulting in subsequent emotion congruent judgments. On the other hand, a person's emotional state may be used as a benchmark to contrast one's subsequent romantic evaluation to, therefore resulting in subsequent emotion incongruent judgments. If the latter would be the case, we would expect the impact of the emotional state onto the subsequent judgment to be mediated by experienced romantic desire towards the previous person. Finally, one can also argue that prior emotions are considered irrelevant for people when making subsequent person judgments, and thus will not exert an impact on the desire people report towards a new interaction partner. Sometimes it is for instance suggested that only unattributed feelings may infuse into subsequent judgments, and that emotions, which are often consciously linked to a cause, may show less effects on judgments of other objects and events (e.g., Schwarz, 1990). However, although in some studies correctly attributed feelings failed to influence subsequent judgments, in numerous other studies, they still had an impact on the subsequent judgment (see Forgas, 1995 for an overview).

We examined the potential role of perceivers' prior state emotions on their judgments of romantic desire, using data from speed-dating events. One hundred and thirty-six individuals dated with multiple potential partners in a series of four-minute interactions, before evaluating these partners' romantic potential. After every date, they filled in questions about their emotions and about evaluations of the potential partner, and at the end of the evening they decided whom they wanted to meet again. This sort of study benefits from high ecological 
validity (participants can initiate a real romantic relationship) and high external validity (with large participant samples), while it is still a well-controlled setting (e.g., Finkel \& Eastwick, 2008; Finkel, Eastwick, \& Matthews, 2007). Additionally, it enables us to investigate the sequential emotional effects of the participants not only on their romantic desire towards someone, but also on their decision to want to see this person again. Finally, it enables us to investigate which emotions matter most, and potentially mediating pathways such as romantic desire towards previous persons. By doing this, we aim to obtain more insight in the processes involved in romantic desire and partner choice, and the understudied role of individuals' emotions in it.

\section{Method}

\section{Participants}

Participants were recruited by advertisements, social media channels, and mailing lists $(N$ $=144)$ as part of a project investigating emotions in initial romantic desire (Pe, Gotlib, Van Den Noortgate, \& Kuppens, 2016). They were informed that the speed-dating events were research-based and free of charge, and they did not receive any monetary compensation in return (as the participation was considered to be a reward in its own right). In the end, 136 Belgian, single individuals attended a speed-dating event where they would meet people of the opposite sex (67 men and 69 women). This sample size was chosen based on a priori power analysis to have sufficient power (.80) to detect small to medium effect sizes (.25) for between person correlations. Age ranged from 20 to 33 years old $(M=25.04, S D=3.24)$. No participant was excluded from further analyses.

\section{Procedure}

To register for the speed-dating events, participants filled in an informed consent and a questionnaire assessing background variables online. Based on this questionnaire, they were 
assigned to different sessions (there were 6 in total) according to age. Four sessions were held for people younger than 27, two sessions were held for people of 27 and older. This resulted in each participant having a series of 10 to 12 "dates" during the speed-dating session.

For the speed-dating sessions, procedures were used that are conventional for speeddating events. Each session took place in the same bar, with tables and chairs positioned throughout the space in a suitable manner. Participants were collectively informed about the set-up of the evening, and were then assigned seats, so that the first "date" could start. Each date lasted four minutes, and a research assistant blew a whistle to signal that participants should rotate to their next speed-date. To reduce potential biases associated with who physically approaches the other (Finkel \& Eastwick, 2009), men and women rotated in alternate fashion to the next date.

All attendants received a booklet before starting the series of dates, and completed a number of questions on their baseline emotions. After each date, they had two minutes to fill in a new sheet of questions, again on their emotions, and on the evaluation of their interaction partner. At the end of the evening, they filled in a last sheet, which contained the pictures of all their interaction partners, and marked who they wanted to meet again. In case there was a match (two speed-daters mutally agreeing to wanting to see each other again), they were provided with each other's contact details the following day.

\section{Materials}

Emotions. Participants indicated how sad, relaxed, anxious, nervous, bored, happy, excited, interested, in love, and irritated they felt at each measurement moment on a scale from 1 = strongly disagree to $5=$ strongly agree ("At this moment, I feel .."). For positive emotions (PE), the average of feeling relaxed, happy, excited, interested, and in love was calculated. Because each participant reported on his/her emotions multiple times that evening, 
emotions were nested in participants, and reliability was calculated following recommendations for multilevel modeling analyses of Shrout and Lane (2012). This means that reliability is calculated both between- and within persons. The between-person reliability indicates the reliability between people's average responses on items (e.g., does a person with a higher average score of happiness also have a higher average score of feeling relaxed) and equaled .98 for positive emotions in our study. The within-person reliability, or how consistently emotions within a person changed together across time (e.g., if a person is feeling happier at a certain time point, is he/she also feeling more relaxed), was .61 for positive emotions ${ }^{1}$. For negative emotions (NE), the average of feeling sad, irritated, bored, nervous, and anxious was calculated (between-person reliability $=.94$, within-person reliability $=.38$ ). The low within-person reliabilities indicate that for both positive and negative items, the items did not change consistently together across time (e.g., an increase in nervousness did not necessarily go together with an increase in feeling bored). Therefore, the effects of specific prior emotions on romantic desire towards the following interaction partner could also differ, and by consequence, we decided to report additional analyses for each positive and negative emotion item separately.

Romantic desire. Participants' romantic desire for their interaction partner was assessed after each interaction, by their ratings of three items (with $1=$ strongly disagree to 5 = strongly agree): "I felt attracted to my interaction partner", "I found my interaction partner physically attractive", "I would like to see my interaction partner again". The average of these three items were calculated (between-person reliability $=.97$, within-person reliability $=.91$ )

Actual choice for interaction partner. At the end of the speed-date event,

\footnotetext{
${ }^{1}$ Shrout and Lane (2012) report on the calculation of within- and between-subject reliabilities for fixed designs, and we followed their recommendations because the time points on which emotions and romantic desire are assessed, correspond to anchor events (the dates; see also Pe, Gotlib, Van Den Noortgate, \& Kuppens, 2016). Similar results were obtained for the multilevel modeling method advised by Nezlek, 2012.
} 
participants indicated for every interaction partner if they wanted to see him/her again (no $=0$, yes $=1$ ), resulting in a binary outcome. Participants indicated in $38.5 \%$ of the cases that they wanted to see an interaction partner again. Descriptive statistics for PE, NE, romantic desire, and separate emotions are reported in Table 1.

<Insert Table 1 here>

\section{Results}

Speed-dating designs have a complex hierarchical data structure with dependencies at the individual, dyadic, and group level, that have to be accounted for. Specifically, every participant rates multiple persons from a different subgroup (here of the opposite sex) on a certain evening (and thus in a certain group). Therefore, we applied a multilevel model that takes into account this assymmetric block design. We modelled random effects for male and female participants separately, and took into account effects on the level of the individual (participant and partner), dyad, and group. Because there was no variance at the group level, the random effect for the group was omitted in the reported analyses (following the advice in Ackerman et al., 2015). This model differs from the Social Relations Model (Ackerman, Kashy, \& Corretti, 2015; Kenny, Kashy, \& Cook, 2006; Kenny, 2007) in that we are not interested in variance partitioning of actor (perceiver), partner (target) and relationship effects. ${ }^{2}$ Instead, we are interested in how two perceiver variables (prior emotions and romantic desire/actual choice) relate to each other over time within-persons.

To investigate the association between prior emotions and judgments of romantic desire, we regressed participants' romantic desire after interaction on their emotion prior to the interaction. Concretely, self-reported desire at time $t$ was predicted by self-reported PE at

\footnotetext{
${ }^{2}$ In the Social Relations Model, actor effects represent the consistency of a person's rating across all partners. This person is also often reffered to as the perceiver. Partner effects reflect the degree to which a person is rated similarly by their partners (targets). Relationship effects capture the unique effects of a perceiver towards a specific target.
} 
time $t-1$. We estimated the general effects, and included gender (coded as -1 for men and 1 for women; Ackerman et al., 2015) as a main and interaction effect so that possible gender differences, if any, would be detected.

A similar model was constructed for NE, and afterwards also for specific emotions. The predictors were person-mean centered, so that they represented state affect, and were not confounded with participants' overall experienced mood during the evening. These analyses were conducted with SAS PROC MIXED. Figure 1 represents an overview of the effects of $\mathrm{PE}$ and NE at time $t-1$ on romantic desire and actual choice at time $t$, Table 2 represents the effects for all specific emotions.

\section{$<$ Insert Figure 1 here>}

We found that participants' self-reported positive emotions after a prior interaction negatively predicted their romantic desire towards their dates, evidencing a contrast effect (see Figure 1), with no differences between men and women, $B=-0.02$, $\mathrm{SE}=0.05, p=.73,95$ $\%[-0.11,0.08]$. Thus, the more positive participants felt entering a conversation, the less attracted they reported to be to their interaction partner afterwards.

For negative emotions, we observed the opposite: negative emotions prior to an interaction positively predicted romantic desire after the interaction. This effect was moderated by gender, $B=-0.16, \mathrm{SE}=0.07, p=.02,95 \%[-0.29,-0.03]$. Modelling fixed effects for men and women separately by the use of dummy variables, revealed that whereas prior negative emotions did positively predict romantic desire in men, $B=0.33, \mathrm{SE}=0.10, p$ $<.001,95 \%[0.14,0.52]$, it did not predict romantic desire in women, $B=0.01, \mathrm{SE}=0.09, p$ $=.93,95 \%[-0.18,0.19] .{ }^{3}$ To obtain an indication of the sizes of these effects, we calculated the percentages of variance in romantic desire explained by prior positive and negative

\footnotetext{
${ }^{3}$ We also carried out models that controlled for the current emotion or emotion at time t. Controlling for current emotion did not change these results. Prior emotions thus impacted romantic desire towards an interaction partner, above and beyond the emotions elicited by this partner (for PE, $p<.0001$, for NE, $p=.0003$ ).
} 
emotions. Specifically, we computed pseudo R-squared measures to assess how much of the male and female's total variance in their romantic desire was accounted for by adding positive or negative emotions to the models (see the supplementary materials of Ackerman et al., 2015 on how to do this). Participants' prior positive emotions explained $13 \%$ of the male participants' and $9 \%$ of the female participants' romantic desire reports. Participants' prior negative emotions explained $14 \%$ of the male participants' and $4 \%$ of the female participants' romantic desire reports.

Next, we assessed the effects of separate prior emotions on romantic desire (see Table 3, Models 1). Regarding positive emotions, feeling interested, happy or excited before the interaction negatively predicted romantic desire for the interaction partner afterwards. Feeling relaxed or in love beforehand had no significant negative effects on romantic desire towards the interaction partner. Regarding negative emotions, feeling irritated or bored beforehand positively predicted romantic desire towards the interaction partner, and feeling sad showed a similar trend in this direction, whereas feeling anxious or nervous beforehand did not predict romantic desire towards the interaction partner. There were no substantial gender differences in these effects, except for the effect of prior anxiety $(B=-0.08, \mathrm{SE}=0.04, p=.03,95 \%[-$ $0.16,-0.01])$. However, when modelling the effects for men and women separately, feeling anxious beforehand did not predict romantic desire in men or women (for men: $B=0.08, \mathrm{SE}$ $=0.06, p=.15,95 \%[-0.03,0.19]$, for women: $B=-0.08, \mathrm{SE}=0.05, p=.14,95 \%[-0.19$, $0.03])$.

$<$ Insert Table 2 here>

Second, to investigate the association between prior emotions and actual choice for the interaction partner at the end of the evening, we predicted participants' actual dating choice for an interaction partner by their emotion prior to the interaction. Again, we did this separately for PE, NE, and the specific emotions, and with person-mean centered predictors. 
Because in these models the dependent variable was binary, we used logistic models, conducting the analyses with SAS PROC GLIMMIX. Prior positive emotions did not predict actual choice in participants (although trending in that direction, with $p=.07$; see Figure 1), and there were no differences according to gender, $B=-0.06, \mathrm{SE}=0.15, p=.71,95 \%[-0.35$, 0.24]. Prior negative emotions did not predict actual choice in participants overall (see Figure 1), but this effect differed for men and women, $B=-0.60, \mathrm{SE}=0.22, p=.006,95 \%[-1.03$, 0.18]. ${ }^{4}$ In men, prior negative emotions did positively predict actual choice $(B=1.01, \mathrm{SE}=$ $0.31, p=.001,95 \%[0.40,1.63])$, but this was not the case in women $(B=-0.20, \mathrm{SE}=0.31, p$ $=.53,95 \%[-0.80,0.41])$. Experiencing more negative emotions beforehand increased the odds of choosing for the date by 2.75 in men.

Separate analyses for specific positive emotions revealed only a negative effect of feeling interested beforehand on actual choice for the interaction partner (see Table 2, Models 2). There was no gender difference in this effect. Analyses for specific negative emotions showed that although reports of boredom, anxiousness or nervousness did not matter for actual choice for the next date, feeling irritated or sad did positively predict actual choice for the next partner (see Table 2, Models 2). The effects of feeling nervous and anxious beforehand were moderated by gender. Specifically, whereas feeling nervous beforehand positively predicted actual choice in men $(B=0.37, \mathrm{SE}=0.12, p=.002,95 \%[0.14,0.60])$, it negatively predicted actual choice in women $(B=-0.26, \mathrm{SE}=0.12, p=.04,95 \%[-0.51,-$ 0.02]). Feeling anxious beforehand did not predict actual choice in men $(B=0.24, \mathrm{SE}=0.17$, $p=.15,95 \%[-0.09,0.57])$, but had a positive effect on women $(B=-0.35, \mathrm{SE}=0.20, p=$ $.07,95 \%[-0.74,0.03])$.

\footnotetext{
${ }^{4}$ Again, we carried out models that controlled for the current emotion or emotion at time t. When we controlled for current emotion, both prior positive and negative emotions positively predicted actual choice at time $t$ (for PE: $p=.03$, for NE: $p=.003$ ).
} 
Next, in follow-up analyses, we examined whether the found effects of prior positive and negative emotions on romantic desire could be explained by experienced desire towards the previous partner, which would provide further evidence for a contrast effect. If participants used their experienced emotion as a reference standard and an indicator for how attracted they were towards the previous date, this means that comparison processes overruled the basic emotion spreading processes. To this end, we examined if the effects of self-reported state emotions at time $t-1$ on participants' romantic desire at time $t$ were mediated by romantic desire at time $t-1$. We used multilevel mediation analyses (more specifically lower level mediation models or 1-1-1 models with random intercepts; Krull \& MacKinnon, 2001; Pituch, Whittaker, \& Stapleton, 2005). Specifically, we applied unconflated multilevel mediation modeling by within-person centering the predictor and mediator so that within and between components of the effects would not be conflated (MacKinnon, 2008). ${ }^{5}$ Gender was added as a moderating factor.

We examined mediation by a series of different multilevel models, again performing these analyses separately for positive and negative emotions (see Figure 2 and 3). In a first model, we predicted romantic desire at time $t-1(\mathrm{M})$ from emotion at time $t-1(\mathrm{X})$ (resulting in a coefficient $B$ a), including gender as a main and interaction effect. In a second model, we predicted romantic desire at time $t(\mathrm{Y})$ from romantic desire $(\mathrm{M})$ and emotion $(\mathrm{X})$ at time $t-1$ (resulting in a coefficient $B \mathrm{~b}$ for desire at time $t-1$ ), again including gender as a main and interaction effects. The product of the estimates of the coefficients of $B \mathrm{a}$ and $B \mathrm{~b}$ then represents the mediated indirect effect of prior emotion on judgments through romantic desire

\footnotetext{
${ }^{5} \mathrm{We}$ report results for multilevel modeling opposed to multilevel structural equation modeling, which is sometimes advocated to use to avoid biased between-person effects (e.g., Preacher, Zhang, \& Zyphur, 2010). We do this because the performance of multilevel mediation modeling for 1-1-1 models has been explicitly evaluated through simulation studies (Krull \& MacKinnon, 2001; Pituch, et al., 2005), and our focus is on within-person effects. Applying multilevel structural equation modeling did, however, not impact the significance of the indirect mediated effects.
} 
towards the previous interaction partner $^{6}$. For positive emotions, we found a significant mediation effect of romantic desire towards the previous partner, with $B \mathrm{a} B \mathrm{~b}=-0.16, \mathrm{SE}=$ $0.03,95 \%$ CI $[-0.23,-0.10]$ (see Figure 2) ${ }^{7}$. For negative emotions, we found equivalent effects, with $B \mathrm{aBb}=0.08, \mathrm{SE}=0.02,95 \% \mathrm{CI}[0.04,0.12]$ (see Figure 3). The effects of prior positive and negative emotions on people's romantic desire towards a new interaction partner were mediated by how much romantic desire they reported towards the previous partner. ${ }^{8}$

$<$ Insert Figure 2 here>

$<$ Insert Figure 3 here >

To investigate if prior emotion would still exert a similar effect on judgments on top of what could be explained by romantic desire towards the previous interaction partner, we conducted additional analyses. Specifically, we investigated if and what impact the emotion that was experienced at the beginning of the evening, when participants did not have had any date yet, exerted on reported desire towards the first interaction partner. To this end, we conducted regression models in which the person-centered version of the positive or negative emotion at the beginning of the evening was entered as a predictor for desire towards the first date. Additionally, we conducted logistic models in which the same emotions were used to predict actual choice at the end of the evening. Each time, gender was added as a main and interaction effect. How positive participants felt at the beginning of the evening now marginally negatively predicted romantic desire towards the first interaction partner, with $\beta=$

\footnotetext{
${ }^{6}$ The asymmetric confidence limits approach (based on the distribution of the product of two normal random variables; MacKinnon, Lockwood, \& Williams, 2004; Tofighi \& MacKinnon, 2011) was used to determine significance of the indirect mediated effects, which follows the suggestion of Pituch et al. (2005).

${ }^{7}$ We do not talk about full or partial mediation as there is a high likelihood of erroneously concluding that complete mediation has occurred because power for testing direct effects in these models is low (Pituch et al., 2005).

${ }^{8}$ To examine if the effect of prior negative emotions on actual choice for a date in men was mediated by desire to the previous interaction partner, we would have to apply lower level mediation models with a binary outcome. However, implementations of mediation analyses with binary outcomes have not been extended yet to multilevel designs (Hertzog, 2017). Therefore, we were unable to perform such analyses and report the results in the manuscript.
} 
$-0.34, t(126)=-1.90, p=.06, R^{2}=.19$, and decreased the chance of selecting this interaction partner at the end of the evening with an odds ratio of $0.34(\chi 2(1)=5.28, p=.02)$. How negative participants felt at the beginning of the evening failed to predict how attracted they were towards their first date $\left(\beta=0.22, t(126)=0.91, p=.36, R^{2}=.17\right)$ or their actual choice for this person $(\chi 2(1)=0.18, p=.75, \mathrm{OR}=1.19)$. There were no significant interactions with gender for both positive and negative emotions (all $p>.05$ ). Conducting analyses for each specific emotion separately revealed that the effects of positive emotions on initial romantic desire were mainly driven by how excited participants felt (with the effect of feeling excited being in a similar direction), whereas the effects on actual choice later on were mainly driven by how relaxed, and marginally by how happy and interested they were feeling (see Table 3 ). There were no differences in these effects between men and women (all $p>.05$ ).

\section{Discussion}

We examined the role of a perceiver's prior emotional state on interpersonal desire in a speed-dating study. We found that the more positive participants felt when entering an interaction, the less desire they reported towards the interaction partner afterwards, and this seemed mainly driven by feeling happy, excited, or interested. The more negative participants felt, particularly in terms of feeling irritated or bored, the more desire they reported. This effect of prior negative emotions on reported desire was mainly visible in men (opposed to women), whereas the effect of prior positive emotions did not differ across gender. The found contrast effects were mediated by romantic desire towards the interaction partner that came before.

With regards to the effects of emotional states on actual decisions of wanting to see someone again, higher prior positive emotions did not predict the choice for an interaction partner (but specifically feeling interested beforehand did), and this effect did not differ 
between men and women. The effect of prior negative emotions on actual choice for the interaction partner differed between men and women. Higher prior negative emotions increased the choice for one's interaction partner in men, but not in women. The intensity of feeling sad or irritated did increase the probability that the following interaction partner was chosen for men and women.

The observed contrast effects of prior emotions on romantic desire were not exclusively due to desire towards a previous partner, or at least not for positive emotions. Even when positive emotions could not be caused by romantic desire towards the previous interaction partner because participants had not met anyone yet, more intense positive feelings marginally negatively predicted how much one liked a subsequent interaction partner and decreased the participants' actual choice for this partner. The contrast effects of negative emotions on romantic desire and choice did disappear when these emotions could not result from romantic desire towards an alternative partner. One possibility is that these effects of negative emotions were driven by people being relieved to be able to escape from an awkward or negative situation, and that the new interaction partner benefitted from this by association.

The finding that prior emotions resulted in emotion-incongruent judgments, stands in sharp contrast to the emotion-congruent biases researchers find when examining the influence of emotion on interpersonal desire judgments (e.g., Forgas \& Bower, 1987; Gouaux, 1971; Gouaux \& Summers, 1973), but is consistent with the inclusion/exclusion model of Schwarz and Bless (2007). People seemed to use their prior emotions as a reference standard to compare the target of judgment. This means that when people were experiencing more positive feelings before entering a date with the target, the target was rated relative to a more positive standard or scale anchor, and therefore evaluated more negatively. On the contrary, when people were experiencing more negative feelings (due to a previous date), the target was 
rated relative to a more negative scale anchor, and therefore came out better. Thus, the judgment shifted away from the information derived from one's pre-existing mood.

It is notable that the effect of prior negative emotions on both desire towards and choice for a partner was stronger in men than in women. This gender difference disappeared when only the first negative emotion of the evening was looked at, and thus seemed to be due to its effects on desire towards the previous partner. We are not aware of research showing gender differences in the effects of emotion on judgments, but men seem to be more susceptible for contrast effects in romantic judgments than women (Barghava \& Fisman, 2014; Kenrick et al., 1989; Kenrick, Neuberg, Zierk, \& Krones, 1994). This does not explain, however, why we only found evidence for this gender difference in negative emotions, and not in positive emotions. One potential reason can be that men experience more negative emotions that are other-oriented (thus focused on the previous date), while women experience more negative emotions that are self-oriented (Cross \& Madson, 1997; Joon, 2007).

Our findings illustrate that something seemingly mundane and beyond one's control, such as to whom the person of interest has previously been talking to or how positive he or she was feeling when entering a bar, can have consequences for the subsequent romantic dynamics that evolve. The effects of positive emotions were only short-lived, but the effects of negative emotions lasted longer, at least in men. This is partly consistent with research showing that negative emotions have more impact and are longer-lasting than positive ones (Baumeister, Bratslavsky, Vohs, \& Finkenauer, 2001). However, even the short-lived effects can already have practical consequences. People form judgments about new persons very quickly (Willis \& Todorov, 2006) and these judgments determine if they start, continue or withdraw from the interaction. It seems that, especially in a sequential setting, it is better not to completely rely on your immediate "gut reaction", but to give it some time. For speeddating researchers not interested in contrast effects and for speed-dating organizers, our 
findings imply that it is better to ask people to form a judgment at the end of all speed-dates instead of immediately after each date. With regards to dating in general, people better judge potential targets on their own (although a positive mood can still exert an influence then) instead of in a sequential setting. This is consistent with one of the common remarks on modern dating methods, which almost always involve sequential methods: they invite comparison, which can lead people to take information into account that otherwise wouldn't be considered (Finkel et al., 2012).

Besides being immediately practically relevant, these findings have broader implications as well. Judgments on romantic desire are not the only interpersonal judgments that are often made in sequence in daily life. Many evaluative person judgments have a sequential component to them. If emotion-congruency effects do not generalize from static judgments to sequential ones, this has important implications for decision making and judgments in a wide variety of settings, ranging from the grading of students to making first impressions. This finding highlights the need to investigate multiple ecologically valid settings, and the specific components to them, to further disentangle the specific influences emotions might have on judgments. At the same time, our findings also suggest potential boundaries to the influence of prior emotional state on judgments, as time span mattered: the prior (positive) emotional state exerted an influence on immediate romantic judgments, but failed to impact the final dating decision at the end of the evening. Theoretically, this indicates the importance of investigating time persistence of emotion effects on judgments to obtain more insight in its underlying mechanisms.

Our choice for a well-controlled, highly ecologically valid setting has the drawback that the associations between prior emotional state, romantic desire and dating choice are correlational, preventing us from making direct causal inferences. An important direction for future research would be to compare in an experiment if prior irrelevant, emotion-inducing 
experiences versus relevant prior emotions, related to romantic judgments, would have the expected effects on subsequent romantic desire. For instance, relevant moods could be induced by providing the participants beforehand with a negative or positive romantic interaction experience (letting them interact with an interested, empathic vs uninterested, harsh confederate of the same attractiveness as the subsequent target of judgment).

Additionally, at this moment, it is unclear if the contrast effects found indeed generalize to other domains, and therefore future research is needed. Further, another open question is if our findings also apply to "regular dating", in which people encounter dates with larger intervals in between. We would speculatively suggest that it does for very extreme emotions, because they could be incorporated as a reference standard. Finally, it was intruiging that some emotions (e.g., interest) impacted romantic desire and actual choice for an interaction partner more than others, and that more positive emotions at the beginning of the evening reduced the chance of choosing for a first interaction partner, whereas more negative emotions had no impact. Future research is needed to see if these findings would replicate.

\section{Conclusion}

Numerous studies have shown that feelings might influence judgments of different kinds. In daily life, evaluative judgments are often made in quick succession, however, which might impact how emotions would precisely guide such evaluative judgments. In a speeddating context, where people explicitly judge potential romantic partners sequentially, we found that romantic judgments contrasted with the mood participants were in upon starting an interaction, and that this was mediated, but not fully explained, by romantic desire to the previous interaction partner. By demonstrating this relationship, this study contributes to a comprehensive understanding of the underlying processes and consequences of emotioneffects in judgments. 


\section{References}

Abele, E. A., \& Gendolla, G. H. (1999). Satisfaction judgments in positive and negative moods: effects of concurrent assimilation and contrast producing processes. Personality and Social Psychology Bulletin, 25(7), 883-895. doi:10.1177/0146167299025007010

Ackerman, R. A., Kashy, D. A., \& Corretti, C. A. (2015). A tutorial on analyzing data from speed-dating studies with heterosexual dyads. Personal Relationships, 22(1), 92-110. doi:10.1111/pere.12065

Barghava, S., \& Fisman, R. (2014). Contrast effects in sequential decisions: evidence from speed dating. Review of Economics and Statistics, 96(3), 444-457. doi:10.1162/REST_a_00416

Baumeister, R. F., Bratslavsky, E., Vohs, K. D., \& Finkenauer, C. (2001). Bad is stronger than good. Review of General Psychology, 5(4), 323-370. doi:10.1037//10892680.5.4.323

Blanchette, I., \& Richards, A. (2010). The influence of affect on higher level cognition: a review of research on interpretation, judgement, decision making and reasoning. Cognition and Emotion, 24(4), 561-595. doi:10.1080/02699930903132496

Bless, H., \& Schwarz, N. (2010). Mental construal and the emergence of assimilation and contrast effects: the inclusion/exclusion model. Advances in Experimental Social Psychology, 42, 319-374. doi:10.1016/S0065-2601(10)42006-7

Bless, H., Igou, E. R., Schwarz, N., \& Wänke, M. (2000). Reducing context effects by adding context information: The direction and size of context effects in political judgment. Personality and Social Psychology Bulletin, 26(9), 1036-1045.

Bower, G. H. (1981). Mood and memory. American Psychologist, 36(2), 129-148. doi:http://dx.doi.org/10.1037/0003-066X.36.2.129

Bower, G. H. (1991). Mood congruity of social judgments. In J. P. Forgas, Emotion and social judgments (pp. 31-53). Oxford: Pergamon Press.

Clore, G. L., Schwarz, N., \& Conway, M. (1994). Affective causes and consequences of social information processing. In R. S. Wyer, \& T. K. Srull, Handbook of Social 
Cognition, Second Edition: Volume 1: basic processes (pp. 323-417). New York: Psychology Press.

Cross, S. E., \& Madson, L. (1997). Models of the self: self-construals and gender. Psychological Bulletin, 122(1), 5-37.

Finkel, E., \& Baumeister, R. (2010). Desire and rejection. In R. F. Baumeister, \& E. J. Finkel, Advanced social psychology: the state of the science (pp. 419-459). New York: Oxford University Press.

Finkel, E. J., \& Eastwick, P. W. (2008). Speed-dating. Current Directions in Psychological Science, 193-197. doi:10.1111/j.1467-8721.2008.00573.x

Finkel, E. J., \& Eastwick, P. W. (2009). Arbitrary social norms influence sex differences in romantic selectivity. Psychological Science, 20(10), 1290-1295. doi:10.1111/j.14679280.2009.02439.x

Finkel, E. J., Eastwick, P. W., Karney, B. R., Reis, H. T., \& Sprecher, S. (2012). Online dating: a critical analysis from the perspective of psychological science. Psychological Science in the Public Interest, 13(1), 3-66. doi:10.1177/1529100612436522

Forgas, J. P. (1995). Mood and judgment: the affect infusion model (AIM). Psychological Bulletin, 39-66. doi:http://dx.doi.org/10.1037/0033-2909.117.1.39

Forgas, J. P. (2008). Affect and Cognition. Perspectives on Psychological Science, 3(2), 94101. doi:10.1111/j.1745-6916.2008.00067.x

Forgas, J. P., \& Bower, G. H. (1987). Mood effects on person-perception judgments. Journal of Personality and Social Psychology, 53(1), 53-60.

Forgas, J. P., Bower, G. H., \& Krantz, S. E. (1984). The influence of mood on perceptions of social interactions. Journal of Experimental Social Psychology, 20(6), 497-513.

Gouaux, C. (1971). Induced affective states and interpersonal desire. Journal of Personality and Social Psychology, 20(1), 37-43.

Gouaux, C., \& Summers, K. (1973). Interpersonal desire as a function of affective state and affective change. Journal of Research in Personality, 7, 254-260.

Han, S., Lerner, J. S., \& Keltner, D. (2007). Feelings and consumer decision making: the appraisal tendency framework. Journal of Consumer Psychology, 158-168. 
Hertzog, M. (2018). Trends in Mediation Analysis in Nursing Research: Improving Current Practice. Western journal of nursing research, 40(6), 907-930.

Isen, A. M. (2001). An influence of positive affect on decision making in complex situations: theoretical issues with practical implications. Journal of Consumer Psychology, 11(2), 75-85.

Joon, J. S. (2007). Gender differences in strain, negative emotions, and coping behaviors: a general strain theory approach. Justice Quarterly, 523-553.

Kenny, D. A. (2007). Estimation of the SRM using specialized software. Opgehaald van davidakenny. net/doc/srmsoftware. doc.

Kenny, D. A., Kashy, D. A., \& Cook, W. L. (2006). Dyadic data analysis. New York: Guilford Press.

Kenrick, D. T., \& Gutierres, S. E. (1980). Contrast effects and judgments of physical attractiveness: when beauty becomes a social problem. Journal of Personality and Social Psychology, 38(1), 131-140.

Kenrick, D. T., Gutierres, S. E., \& Goldberg, L. L. (1989). Influence of popular erotica on judgments of strangers and mates. Journal of Experimental Social Psychology, 159167. doi:10.1016/0022-1031(89)90010-3

Kenrick, D. T., Neuberg, S. L., Zierk, K. L., \& Krones, J. M. (1994). Evolution and social cognition: contrast effects as a function of sex, dominance, and physical attractiveness. Personality and Social Psychological Bulletin, 20(2), 210-217.

Krull, J. L., \& MacKinnon, D. P. (2001). Multilevel modeling of individual and group level mediated effects. Multivariate behavioral research, 36(2), 249-277.

Lerner, J. S., \& Keltner, D. (2000). Beyond valence: toward a model of emotion-specific influences on judgement and choice. Cognition and Emotion, 473-493. doi:10.1080/026999300402763

MacKinnon, D. P. (2008). Introduction to statistical mediation analysis. New York: Erlbaum.

MacKinnon, D. P., Lockwood, C. M., \& Williams, J. (2004). Confidence limits for the indirect effect: distribution of the product and resampling methods. Multivarate behavioral research, 99-128. doi:10.1207/s15327906mbr3901_4 
Nezlek, J. B. (2012). Multilevel modeling analyses of diary-style data. In M. R. Mehl, \& T. S. Conner, Handbook of research methods for studying daily life (pp. 357-383). New York: The Guilford Press.

Pe, M. L., Gotlib, I. H., Van Den Noortgate, W., \& Kuppens, P. (2016). Revisiting depression contagion as a mediator of the relation between depression and rejection: a speeddating study. Clinical Psychological Science, 4(4), 675-682. doi:10.1177/2167702615602672

Pituch, K. A., Whittaker, T. A., \& Stapleton, L. M. (2005). A comparison of methods to test for mediation in multisite experiments. Multivariate Behavioral Research, 40(1), 1-23. doi:10.1207/s15327906mbr4001_1

Preacher, K. J., Zhang, Z., \& Zyphur, M. J. (2010). A general multilevel SEM framework for assessing multilevel mediation. Psychological Methods, 15(3), 209-233. doi:10.1037/a0020141

Schwarz, N. (1990). Feelings as information: informational and motivational functions of affective states. In E. T. Higgins, \& R. M. Sorrentino, Handbook of motivation and cognition: foundations of social behavior (pp. 527-561). New York: Guilford Press.

Schwarz, N. (2011). Feelings-as-information theory. In P. A. Van Lange, A. W. Kruglanski, \& T. E. Higgins, Handbook of Theories of Social Psychology: Collection: Volumes 1 \& 2 (pp. 289-308). Thousand Oaks, CA: SAGE publications LTD.

Schwarz, N., \& Bless, H. (1992). Constructing reality and its alternatives: assimilation and contrast effects in social judgments. In L. M. L., \& A. Tesser, The construction of social judgments (pp. 217-245). Hillsdale: NJ: Erlbaum.

Schwarz, N., \& Bless, H. (2007). Mental construal processes: the inclusion/exclusion model. In D. A. Stapel, \& J. Suls, Assimilation and contrast in social psychology (pp. 119141). Philadelphia, PA: Psychology Press.

Schwarz, N., Strack, F., Kommer, D., \& Wagner, D. (1987). Soccer, rooms, and the quality of your life: mood effects on judgments of satisfaction with life in general and with specific domains. European Journal of Social Psychology, 17, 69-79.

Shrout, P., \& Lane, S. P. (2012). Psychometrics. In M. R. Mehl, \& T. Conner, Handbook of research methods in daily life (pp. 302-320). New York: Guilford Press. 
Spielmann, S. S., \& MacDonald, G. (2016). Nice guys finish first when presented second: responsive dates are evaluated more positively following exposure to unresponsive dates. Journal of Experimental Social Psychology, 64, 99-105. doi:http://dx.doi.org/10.1016/j.jesp.2016.02.002

Tofighi, D., \& MacKinnon, D. P. (2011). RMediation: an R package for mediation analysis confidence intervals. Behavior research methods, 43(3), 692-700. doi:10.3758/s 13428-011-0076-x

Willis, J., \& Todorov, A. (2006). First impressions: making up your mind after a 100-ms exposure to a face. Psychological Science, 17(7), 592-598. doi:10.1111/j.14679280.2006.01750.x 
Table 1.

Descriptive Statistics for all Key Variables

\begin{tabular}{lll}
\hline & $M$ & $S D$ \\
\hline Positive emotions & 2.65 & 0.66 \\
Feeling interested & 2.86 & 1.12 \\
Feeling happy & 3.31 & 0.91 \\
Feeling excited & 2.48 & 1.04 \\
Feeling relaxed & 3.33 & 1.03 \\
Feeling in love & 1.26 & 6.35 \\
Negative emotions & 1.29 & 0.36 \\
Feeling anxious & 1.27 & 0.58 \\
Feeling sad & 1.09 & 0.34 \\
Feeling nervous & 1.69 & 0.84 \\
Feeling irritated & 1.15 & 0.45 \\
Feeling bored & 1.27 & 0.60 \\
Romantic desire & 2.88 & 0.99 \\
\hline
\end{tabular}


Table 2.

Multilevel results for the regression coefficients for specific emotions at time $t$ - 1 predicting romantic desire at time $t$, and actual choice at time $t$.

\begin{tabular}{|c|c|c|c|c|c|c|c|}
\hline Model 1 & $B$ & $S E$ & $T$ & $p$ & $95 \% \mathrm{CI}$ & $\begin{array}{l}R^{2} \\
\text { men }\end{array}$ & $\begin{array}{l}R^{2} \\
\text { wom }\end{array}$ \\
\hline \multicolumn{8}{|l|}{ Romantic desire at time $t$} \\
\hline Feeling interested at time & -0.06 & 0.02 & -2.68 & $<.01$ & $-0.10,-0.02$ & 0.15 & 0.07 \\
\hline Feeling happy at time $t-1$ & -0.08 & 0.03 & -2.58 & .01 & $-0.14,-0.02$ & 0.13 & 0.07 \\
\hline Feeling excited at time $t$ - & -0.08 & 0.03 & -2.89 & $<.01$ & $-0.13,-0.02$ & 0.15 & 0.05 \\
\hline Feeling relaxed at time $t$ - & -0.02 & 0.03 & -0.68 & .50 & $-0.07,0.03$ & 0.15 & 0.05 \\
\hline Feeling in love at time $t$ - & -0.06 & 0.05 & -1.20 & .23 & $-0.16,0.04$ & 0.16 & 0.06 \\
\hline Feeling anxious at time $t$ - & -0.00 & 0.04 & -0.02 & .98 & $-0.08,0.08$ & 0.16 & 0.06 \\
\hline Feeling sad at time $t-1$ & 0.10 & 0.06 & 1.68 & .09 & $-0.02,0.22$ & 0.18 & 0.05 \\
\hline Feeling nervous at time $t$ - & 0.01 & 0.03 & 0.48 & .63 & $-0.04,0.06$ & 0.15 & 0.06 \\
\hline Feeling irritated at time $t$ - & 0.15 & 0.05 & 3.20 & $<.01$ & $0.06,0.24$ & 0.18 & 0.05 \\
\hline Feeling bored at time $t-1$ & 0.08 & 0.04 & 2.32 & .02 & $0.01,0.15$ & 0.15 & 0.05 \\
\hline
\end{tabular}

Model 2 $\begin{array}{llllll}B & \text { SE } & T & p & 95 \% \mathrm{CI} \quad \mathrm{OR}\end{array}$

Actual choice at time $t$

$\begin{array}{lllllll}\text { Feeling interested at time } & -0.15 & 0.07 & -2.04 & .04 & -0.29,-0.01 & 0.86\end{array}$

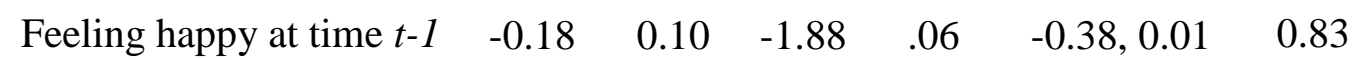

Feeling excited at time $\begin{array}{lllllll}t- & -0.11 & 0.09 & -1.26 & .21 & -0.28,0.06 & 0.90\end{array}$

Feeling relaxed at time $t-\quad 0.01 \quad 0.08 \quad 0.16 \quad \begin{array}{lllll}.87 & -0.15,0.18 & 1.01\end{array}$

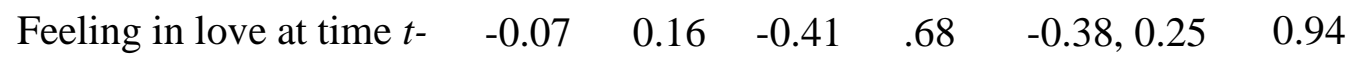




\begin{tabular}{llllllll}
\hline Feeling anxious at time $t-$ & -0.05 & 0.13 & -0.42 & .67 & $-0.31,0.20$ & 0.95 \\
Feeling sad at time $t-1$ & 0.54 & 0.22 & 2.52 & .01 & $0.12,0.97$ & 1.72 \\
Feeling nervous at time $t-$ & 0.05 & 0.09 & 0.62 & .53 & $-0.12,0.22$ & 1.06 \\
Feeling irritated at time $t-$ & 0.38 & 0.15 & 2.50 & .01 & $0.08,0.68$ & 1.46 \\
Feeling bored at time $t-1$ & 0.07 & 0.12 & 0.61 & .54 & $-0.16,0.31$ & 1.08 \\
\hline
\end{tabular}


Table 3.

Results for the regression coefficients for specific emotions at time 1 predicting romantic desire for the first interaction partner (assessed at time 2), and actual choice for this interaction partner.

\begin{tabular}{|c|c|c|c|c|c|c|}
\hline Model 1 & $B$ & $\beta$ & $S E$ & $T$ & $p$ & $R^{2}$ \\
\hline \multicolumn{7}{|l|}{ Romantic desire at time 2} \\
\hline Feeling interested at time 1 & -0.12 & -0.11 & 0.10 & -1.23 & .22 & .18 \\
\hline Feeling happy at time 1 & -0.16 & -0.11 & 0.12 & -1.27 & .21 & .18 \\
\hline Feeling excited at time 1 & -0.18 & -0.16 & 0.10 & -1.86 & .06 & .19 \\
\hline Feeling relaxed at time 1 & -0.16 & -0.14 & 0.10 & -1.68 & .10 & .19 \\
\hline Feeling in love at time 1 & 0.16 & 0.09 & 0.16 & 1.04 & .30 & .18 \\
\hline Feeling anxious at time 1 & 0.09 & 0.06 & 0.12 & 0.78 & .44 & .17 \\
\hline Feeling sad at time 1 & 0.34 & 0.15 & 0.28 & 1.21 & .23 & .18 \\
\hline Feeling nervous at time 1 & 0.01 & 0.01 & 0.09 & 0.13 & .89 & .17 \\
\hline Feeling irritated at time 1 & 0.09 & 0.04 & 0.18 & 0.48 & .63 & .17 \\
\hline Feeling bored at time 1 & 0.13 & 0.08 & 0.14 & 0.94 & .35 & .20 \\
\hline Model 2 & $B$ & $\beta$ & $S E$ & $X^{2}$ chi- & $p$ & $E x$ \\
\hline
\end{tabular}

Actual choice at time 2

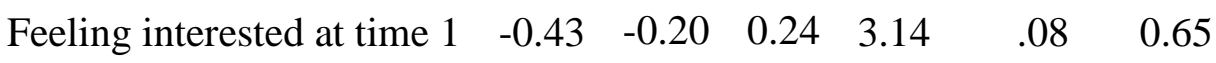

Feeling happy at time $1 \quad-0.58 \quad-0.21 \quad 0.31 \quad 3.53 \quad .06 \quad 0.56$

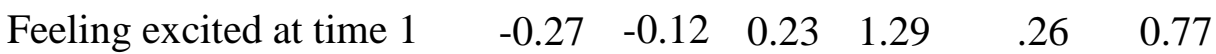

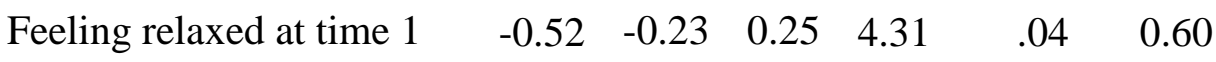




\begin{tabular}{llllllll}
\hline Feeling in love at time 1 & 0.22 & .06 & 0.38 & 0.33 & 0.56 & 1.25 \\
Feeling anxious at time 1 & -0.04 & -0.01 & 0.29 & 0.02 & 0.89 & 0.96 \\
& & & & & & & \\
Feeling sad at time 1 & 0.33 & 0.08 & 0.64 & 0.27 & 0.61 & 1.39 \\
Feeling nervous at time 1 & -0.07 & -0.03 & 0.23 & 0.09 & 0.77 & 0.94 \\
Feeling irritated at time 1 & -0.35 & -0.09 & 0.44 & 0.63 & 0.43 & 0.71 \\
Feeling bored at time 1 & 0.45 & 0.14 & 0.37 & 1.52 & 0.22 & 1.57 \\
\hline
\end{tabular}




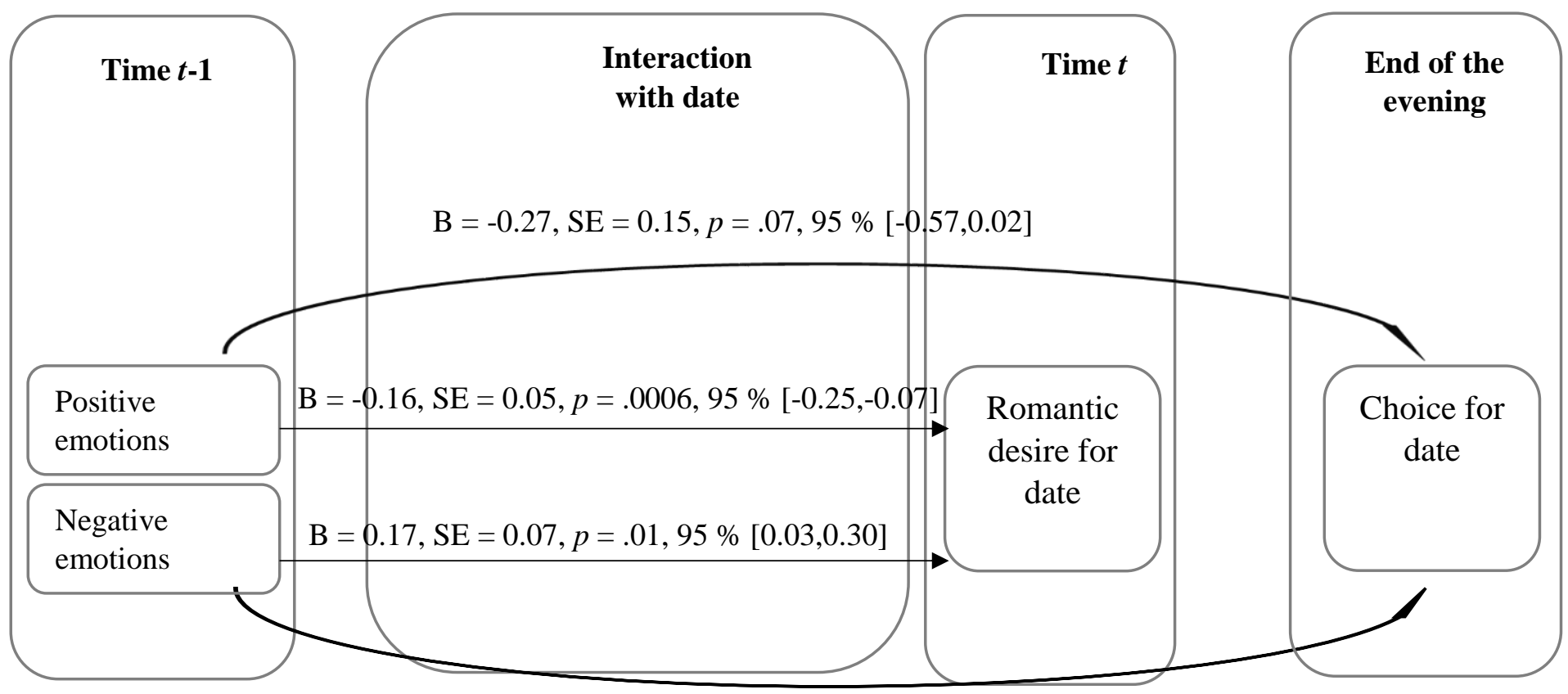

$\mathrm{B}=0.41, \mathrm{SE}=0.22, p=.07,95 \%[-0.03,0.84]$

Figure 1. Overview of the effects of PE and NE at time t-1 on romantic desire and actual choice at time $\mathrm{t}$. 


$$
\mathrm{B}=-0.01, \mathrm{SE}=0.06, p=.82,95 \%[-0.13,0.11]
$$

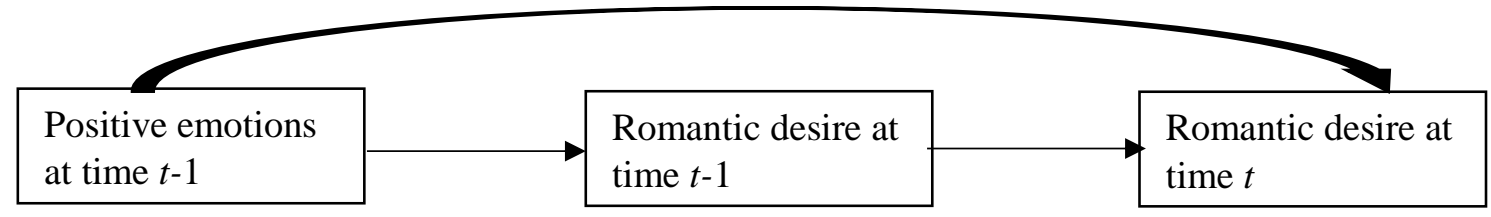

$$
\mathrm{B}=1.03, \mathrm{SE}=0.04, p<.0001,95 \%[0.95,1.11] \quad \mathrm{B}=-0.16, \mathrm{SE}=0.03, p<.0001,95 \%[-0.22,-0.09]
$$

Figure 2. Multilevel mediation model, in which romantic desire at time $t-1(\mathrm{M})$ mediates the effect of positive emotions at time $t-1(\mathrm{X})$ on romantic desire at time $t(\mathrm{Y})$.

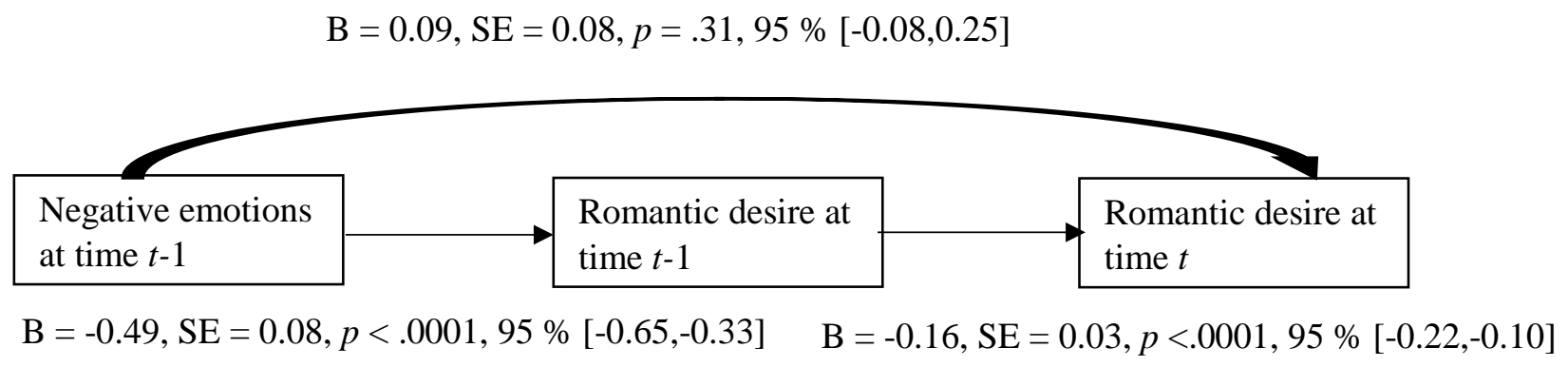

Figure 3. Multilevel mediation model, in which romantic desire at time $t$-1 (M) mediates the effect of negative emotions at time $t-1(\mathrm{X})$ on romantic desire at time $t(\mathrm{Y})$. 